\title{
LEER PARA EXPLICAR-ME, LEER PARA EXPLICAR-LES
}

\section{Ramón Francisco}

A todo lo largo de mi vida literaria he tenido la oportunidad de presentar varios libros de poetas, cuentistas, críticos y novelistas eminentes. Casi todos esos libros son muy estimables joyas literarias. A todos les he prestado atención cuidadosa antes de la presentación, durante la presentación y después de la presentación, pero, en estos momentos no puedo hacer un inventario, más o menos fiel, de las reflexiones más importantes que hube de desarrollar y destacar en el momento de las diversas presentaciones. Debo confesar que este inventario era de gran interés para mí en el instante en que me dispuse a escribir el presente trabajo, al menos para fines de ambientación. Sin embargo, me alegra ahora que fuera una falta que me obligara a pensar seriamente en algo en que no había pensado en lo pasado y que está contenido en una pregunta que parece simple a primera vista: ¿Qué es una presentación de un libro?

Algunas personas se refieren a las presentaciones como actos meramente formales, sin intenciones ulteriores, literarias o extra-literarias,

Puesta en circulación de la obra Los Escritores Dominicanos y la Cultura de José Alcántara Almánzar, Monografía 21, INTEC. 
en los que se acostumbra siempre a brindar un vaso de ron, o de refresco, o de cerveza. Recuerdo que, en son de broma, en la época en que yo era joven, los literatos acostumbrábamos a parodiar las invitaciones a la presentación, o puesta en circulación de un libro observando que ellas deberían mejor decir: "Se invita a un brindis de ron y refresco, en el sitio tal, en la fecha tal, en la hora tal. También se pondrá en circulación un libro."

Un amigo bromista me decía que las presentaciones eran algo así como el bautizo de un infante: un acto mediante el cual se introduce al libro en la corriente tortuosa de la circulación, aún sin que el libro mismo haya dado su anuencia para que así hagan con él, exactamente como el infante bautizado, quien no ha dicho todavía si quiere ser católico, protestante, musulmán o nihilista.

Bueno, cualquiera, si apoyara al amigo, pensaría que, como para parecerse más a un bautizo, el presentador del libro asegura con la presentación un compadrazgo con el autor que evitará, en los casos en que este autor sea un crítico literario, cualquier comentario adverso sobre la obra del presentador (por lo menos, así lo cree él) y, en los casos en que el autor no sea crítico, asegurará la solidaridad de este escritor con la obra del propio presentador (por lo menos, eso cree el presentador).

En muchas ocasiones las presentaciones son actos de lo más apresurados y por cierto que he sabido, o he venido a deducir por presentaciones mismas a las que he asistido, o por lecturas posteriores de libros presentados, que para lograr lo que el presentador cree el compadrazgo sagrado que le evite los peligros y asegure la solidaridad de que he hablado y, también, para hacer su encomienda más fácil de cargar, este presentador ha recurrido a una treta muy favorecida por los lectores falsos y haraganes y, por supuesto, charlatanes: leer la solapa del libro y, por arte y magia de esta solapa, conformar un juicio de presentación basado en lo que ella dice, presentándose a si mismo como un suficiente y cuidadoso lector. Esto es un timo literario y es fácil desenmascarar al timador, quien, merced a su imaginación, como si se tratara del arte de novelar, es capaz de armar toda una descripción de un libro completo, o de una situación real o imaginaria. Ocurre casi siempre que el principal recurso para identificación de un timador tal, consiste en notar que él sólo ha de referirse siempre a lo que dice la solapa del libro, mostrándose evasivo y desmemoriado cuando le hablan y le preguntan sobre, y por 
porciones específicas de la obra. El parece tratar a la solapa como un tema del cual se pudieran escribir múltiples variaciones, como si estuviese componiendo una obra musical.

He conocido solamente a un escritor, en toda mi vida, que no podía absolutamente ser sorprendido en su actitud de novelar, aunque no era muy común verlo presentando libros. El querido y difunto amigo Ramón Lacay Polanco era capaz de contarnos (lo recuerdo vivamente en las mesas del desaparecido restaurante Jai Alai) de qué manera él se robaba el gas en Nueva York, mediante el procedimiento de echar sal sobre el contador, o de qué manera impedía que el contador de luz marcara la energía consumida, y de qué manera el se internaba, en noches frías y oscuras, a través de las calles del China Town, o en las cálidas calles de la ciudad de los artistas, Greenwich Village, en el corazón de Manhattan. Pero ocurre que, en esa época, Lacay jamás había visitado a Nueva York. Y, sin embargo, sus descripciones eran punto a punto extraordinariamente verosímiles. Su tremenda capacidad de novelar era proverbial y es una verdadera lástima que no nos dejara una obra novelística más extensa.

(Ahora bien, para evitar cualquier interpretación apresurada, debo decir, antes de entrar en cualquier otra materia, que José Alcántara Almánzar, en guardia contra la posibilidad de que yo cometiera una charlatanería semejante, quiero decir, leyendo solamente la solapa del libro que hoy me complazco en apadrinar, me entregó una copia de éste aún antes de que la portada estuviera terminada, dejándome entonces "solapadamente" huérfano, pero asegurándose con ello de que yo iba a leer realmente la obra a presentar y no los iba a timar ni a él ni a ustedes.)

Pero hay otra treta a la cual recurren algunos presentadores de vez en cuando.

Ocurre muchas veces que el libro es entregado a la carrera al presentador, con la excusa de que la imprenta es la más incumplidora del mundo porque tardó innecesariamente la terminación de los primeros ejemplares (casi nunca se dice que el autor tardó, a su vez, en abonar la cuota previa a la entrega de los primeros ejemplares) entregándolos sólo algunos muy breves días, a veces horas, antes del acto de la presentación. Tal dilación es una buena excusa, en la opinión del presentador, para no leer el libro y recurrir a la solapa o, si no, a una segunda treta favorita: olvidarse del libro y centrarse en el escritor. 
Lo cual tiene sus peligros, después de todo, ya que, a menos que el presentador decida enredarse detallando cuán buena persona es el autor, cuán estudioso, cuán dedicado, cuán hermosos e inteligentes son sus hijos, cuán de su familia es, que ni siquiera va a un cine por las noches por ver la televisión sentado junto a su esposa, etc., ha de conocer bien la obra anterior del autor, su personalidad literaria, sus temas favoritos, los recursos de sus técnicas más usuales etc., para salir bien del paso. De lo contrario, fallará lamentablemente en su intento y dejará en su auditorio una sanción de deficiencia que, si el presentador tiene mi edad, $o$ anda alrededor de ella, hará que algún que otro asistente al acto de la presentación comente, por lo bajo: "Caramba, bien es verdad que Fulano está ya irremediablemente chochando!".

Un peligro adicional: si el presentador ha de centrarse en el autor y si no recurre a apropiados diques de contención aquí o allá, habrá de terminar presentando a este autor y no a su libro, cosa que pudiera resultar inapropiada porque todos los asistentes a la presentación conocen ya al escritor y, a partir de tal cual cosa, otra vez si el presentador tiene mi edad, o anda alrededor de ella, no faltará algún que otro asistente que exclamará, por lo bajo, "Pero a Fulano ya se le están quemando los cables!".

Ahora bien, la presentación que parece ser más natural ha de referirse tanto al libro como al escritor; ha de ser un comentario sobre la personalidad literaria del escritor y una introducción y acercamiento a los temas del libro, sus propósitos, el lugar en la obra del autor, cómo enriquece o empobrece esta obra, etc.

Aunque se trate de un acto de puesta en circulación, la presentación ha de evitar circular por sobre todo el libro, evitando de esta forma que el presentador aparezca como un tunante, destemplado, arrogante y petulante, quien, queriendo exhibirse con una suficiencia derrochista, ha de terminar cansando al auditorio, bien si los presentes están de pie, porque algunos contrafuertes de zapatos que aprietan más de lo debido, o bien si están sentados, porque, si se trata de hombres, los pantalones usados en estos días ya no son los valunes anchos, frescos y cómodos de tiempos ya idos (a propósito, versiones del valun pueden verse, en todo su airoso garbo, en fotografías viejas de viejos peloteros, sobre todo de la época de aquel célebre campeonato en que compitieron equipos tales como el ñika con K y el San Rafael) y los de ahora (los pantalones) sin lugar a duda que parecen más bien camisas de fuerza, porque aprietan 
ostensiblemente (e innecesariamente, digo yo, porque nunca he podido entender que el hombre haya sido hecho a la medida de los concursos de belleza) y, si se trata de mujeres, bien es cierto que algunas "superminis" de hoy no permiten más de cinco o seis minutos en una misma posición, so pena de comenzar, ellas, por su cuenta, ciertas incómodas y no deseadas escaladas que obligan a las damitas de estos días a mantenerse constantemente estirando la tela, mientras ruegan a Dios que la fuerza con que estiran no la rompa.

Pero, tal parece que, andando por las ramas, me he acercado un poco al meoilo de lo que quiero decir en la presentación del libro de José Alcántara Almánzar "Los Escritores Dominicanos y la Cultura". Sin embargo, me falta todavia una última elucubración. Aclaro que, a todo lo largo de lo que voy a decir mientras elucubro, estaré intentando explicar a José Alcántara Almánzar, aunque no mencione específicamente su nombre en los siguientes párrafos, como crítico y escritor de estos tiempos y el lugar que ocupa en el conjunto de la literatura nacional. Un procedimiento indirecto, por medio del cual pretendo emparentarlo con huestes tales como aquellas a las que pertenecen Horacio, Aristóteles, Elliot, Pound, etc.

La elucubración sigue a continuación:

Me pareció que valía la pena preguntar y contestar al mismo tiempo, ¿Qué es la literatura sino un instrumento de comunicación, quizás el más perfecto de todos? Pregunta tonta y contestación superabundante, porque ambas han sido expuestas muchas veces en lo pasado.

Podemos agregarle, a la literatura, cualesquiera otros adornos florales que querramos. Por ejemplo, la media res de que habló Horacio al comentar la obra de Homero; o podemos definir qué son los hexámetros; o qué los alejandrinos o, qué un hemistiquio; o qué el ritmo; o, qué el estilo; o, qué los sonetos; o qué las glosas; o, qué la épica; o, qué la lírica; en fin, todo a lo que se le dio un nombre adecuado y se lo hizo pertenecer al reino de lo bello, o al reino de lo grotesco también, o al reino de las formas, etc. Por encima de todo esto, sin embargo, estará siempre, aunque lo uno no pueda pasarlo sin lo otro, el "sentido" de la obra literaria individual, o de la obra literaria de un país en su conjunto. Y el "sentido" es lo que la literatura dice, o lo que pretende decir.

Aquel que quiera más que verificar esta afirmación, que se siente un día con un libro de Homero en las manos e interpele al gran rapsoda: ¿Qué es lo que pretende Homero? ¿Qué busca con su obra? 
La manera usada por Homero podrá ser todo lo bella que se quiera y establecer todos los canones literarios que puedan imaginarse. La Humanidad, por los siglos de los siglos, ha de agradecer al poeta su forma literaria, por todo lo que ella ha significado para los escritores posteriores. Sin embargo, aunque ella sea todo lo importante que verdaderamente es, no representa el fin perseguido por Homero, sino el medio de que se vale para perseguir su fin.

Lo que Homero quiere, antes que todo, es narrar, comunicar: En la Ilíada, al hombre griego en la guerra, y, en la Odisea, al hombre griego en la paz. Debido a que él narró a este hombre en tales circunstancias es que las generaciones posteriores han podido estudiar, entender y explicar en gran parte, el origen y comportamiento de este hombre, su paideia, y los valores en los que creían tanto los aqueos, de las hermosas grebas, como los teucros, domadores de caballos.

Es lo mismo que pasa con Virgilio. En vano será que pretendamos aclararle a Virgilio que lo que él quiere es entretener a sus lectores con su Eneida. No. A lo que Virgilio aspira, igual a como lo aspiraba su Emperador, que lo instaba, desde el frente de batalla, con mensajes urgiéndole a que terminara su obra, es a narrar, para la educación de los hombres presentes en y para conocimiento de los hombres venideros, los orígenes supuestamente grandiosos del pueblo romano, única manera de entender y perseguir su Destino imperial.

Por tanto, es mi opinión firme que la literatura pertenece, debido a que es, o debe ser, fuente de conocimiento del hombre en su circunstancia, al grupo de las ciencias históricas. Y no me deja mentir el Decamerón, de Bocaccio, en donde estudiamos hoy a la sociedad de su época, o el Cándido, de Voltaire, obra con la cual este autor intentaba explicar a sus contemporáneos que si bien el mundo era injusto, era el mejor de los mundos posibles.

Y es que aquellos que leyeron solamente a Tucídides y a Heródoto para entender la historia del pueblo griego posiblemente se quedaron incompletos si no leyeron a Homero también, o a Hesíodo y su tratado de los trabajos y los días. Es el conjunto de los libros de la historia, junto con el conjunto de los libros de la literatura, lo que puede explicar el devenir del hombre en una sociedad dada. (Y, en estos momentos, pienso en Walt Whitman).

Quienes hacen la literatura de un país no son solamente los poetas, los novelistas, los dramaturgos, los cuentistas, etc. Por ejemplo, el arte 
de la novela no hubiese podido ser entendido plenamente si Horacio no hubiese explicado cómo el efecto, el encanto y hasta el poder de la narración de Homero se basaba en que tomaba la historia "in media res". Esta era la razón principal por la cual el texto de la Ilíada se convertía entonces en una novela y no quedaba siendo solamente un texto de historia. Desde entonces aprendimos que una narración puede comenzarse aún por su fin, o por su "media res", o por sus inicios mismos. El papel de Homero, en este caso, fue ingeniar el medio y aplicarlo. Pero, ¿Cuál es el papel de Horacio?

Desde el punto de vista de la intención con que uno emprenda la lectura de una obra, puedo definir dos enfoques: a) leer para explicar-me una obra, o b) leer para explicar-les una obra. En tanto que yo, como lector, sólo asuma al literal a), es muy posible que goce la obra, que la comprenda desde mi personal interpretación, etc.-En cambio, en tanto que yo asuma el literal b), la obra debe ser gozada y comprendida pero, para ser "explicada" a otros. Aunque parezca tremendamente simple. hay una diferencia abismal y muy sustancial en los dos enfoques al leer una obra. Y, entonces, hay también una responsabilidad social que descansa sobre los hombros de estos lectores que explican las obras.

Es al grupo de los que asumen el literal b) al cual pertenecen lectores como Horacio. Podemos decir, aunque con ello no intentamos que se asuma siempre un enfoque meramente "sociológico" al leer una obra, que la misión del lector del grupo en que está Horacio cuando explica la "media res" de Homero, es eminentemente social. No es que él tenga que intentar explicar una obra desde los ángulos de masa con que se quiere identificar cualquier referencia a lo "social" que se haga, sino que, siendo la obra de arte literario, especialmente la obra completa de un escritor, una parte del grupo de obras que narran, bien en poesía, bien en drama, bien en cuento, bien en novela, el comportamiento de un hombre, o de un grupo de hombres en un determinado estadio de desarrollo de la sociedad que ellos conforman, valiéndose para ello de temas reales o imaginarios, de peripecias simples o complicadas, o de argumentos fantásticos pero verosímiles, aquel que emprenda la misión de explicar lo que el escritor está tratando de narrar en prosa o en verso, esta llevando al cabo una labor básicamente "social". Una labor de investigación, esclarecimiento y difusión de las significaciones tremebundas de la historia. En esto no cedo. Aún el poeta más subjetivo, por ejemplo, no puede escribir una sola línea, bien se refiera a sus 
sentimientos, o bien no, si no es colgando de los hombres que lo rodean, de su sociedad, en fin, de lo que Ortega y Gasset llamaba "la circunstancia".

Y, es al grupo de lectores como Horacio al cual pertenece con toda propiedad y con las mejores credenciales, José Alcántara Almánzar. Yo así lo he situado desde que, hace ya muchos años, vine a leer los comentarios y juicios contenidos en su primera obra, "Antología de la Literatura Dominicana". Su principal preocupación ha sido siempre entender la obra misma y su imbricación en el cuerpo literario de nuestro país para regalarnos una explicación, un comentario, una crítica de ella que nos permita entender a su autor $y$, por consecuencia, entendernos a nosotros mismos como hombres de nuestros tiempos. Una labor tan importante como necesaria para perseguir nuestro desarrollo como entes humanos, ya que destino imperial no tenemos.

Por supuesto, no se trata de decir que un enfoque aisladamente sociológico agote el estudio de una obra. Creo que José tampoco cree esto. Podría parecer que hay alguna contradicción en lo que afirmo. Se trata de que yo creo que, aún cuando la sociología no estaba "descubierta" en los tiempos de Horacio, de todas formas su explicación de la "media res" sirvió para que mejor entendisemos la obra de Homero. Y es que lo social no es necesariamente lo "sociológico" para los fines a que me estoy refiriendo. Lo social, en mi análisis, va un poco más allá. Va hasta comprender y situar también a Robinson Crusoe en su isla desierta, es decir, al ser alejado de toda sociedad. Porque la propia y supuesta soledad de Robinson Crusoe es su propia y real circunstancia y, por otra parte, él no hubiese podido subsistir si la propia naturaleza vegetal y mineral y animal no lo hubiesen condicionado.

Crítica de arte hemos llamado por mucho tiempo a la labor desarrollada por lectores y escritores del grupo de literal b) de que hablamos más arriba. Para mi, no hay literatura que esté completada si estos escritores críticos no existieran. Ellos no pueden menguar la literatura de un país, pero pueden ensanchar, difundir y dilatar sus efectos. Labor tremendamente importante, porque de lo que se trata es de entender al hombre pasado, o al de hoy, como base para comprender al hombre por venir.

Al leer la obra que hoy apadrino y que entrega a ustedes José Alcántara Almánzar, me siento más que seguro de todo lo que digo porque esta es otra obra con la cual José intenta entender y explicarnos 
a sus semejantes, a través de la explicación de sus hechos literarios particulares. Freddy Gatón Arce, Manuel Rueda, Virgilio Días Ordóñez, Hostos, Pero Henríquez Ureña, etc., son estudiados en muchas de sus obras, examinadas en las particulares circunstancias que les tocó vivir a los escritores. Circunstancias bien adversas, siempre empeoradas por una política cultural de la peor clase, en un país como el nuestro que se ha desenvuelto de tropezón en tropezón; que, de tan vulgares, no son tropezones, sino "trompezones": quiero decir, de Osorio, a Toussaint, a Sánchez Ramírez, a Núñez de Cáceres, a Boyer, a Santana, al Decreto de San Fernando, a Lilís, a Vásquez, a Trujillo y, paro de contar.

Maestro como es José Alcántara Almánzar, y de generaciones, aunque su edad no lo explique, el método con que él nos aproxima a las obras de los escritores de quienes habla en el libro que hoy se pone en circulación es más o menos descriptivo. Este método ha de suponer que no todos los lectores han podido leer todavía la obra comentada, lo cual obliga a recurrir a describir, o con menos, o con más amplitud, la obra misma. Este es el método perfectamente válido para el punto de vista desde el cual explica José una obra. ¿Por qué?

Se trata, en primer lugar, de explicar lo que el escritor está queriendo decir con su obra. El hilo que lleva José a la salida del túnel de la explicación de una obra es eminentemente descriptivo. En el camino, no se crea que no, también se explicarán algunos de los instrumentos que se han usado para lograr decir lo que se deba decir, pero la crítica está centrada principalmente en lo que se dice, si bien cómo se dice debe compadecerse con lo que se dice. Esto es lo que el eminente crítico J. A. Richards llama atender al "sentido" de una obra literaria, y muchas veces este sentido no puede explicarse a menos que no se examinen los instrumentos de que se valió el escritor.

Esto lo ha entendido bien José al comentar la obra de Freddy Gatón Arce, por ejemplo, ya que Freddy obliga constantemente a examinar su recurrencia a palabras y giros arcaizantes y raraizantes, sin lo cual no puede entenderse su poesía. José, en su caso, comenta el lenguaje de Freddy y sus análisis son tan pertinentes como importantes.

Casi siempre la explicación que José da de una obra es clara, llana. Su formación sociológica lo induce a preferir el detalle claro, sin rodeos, sencillo, del "sentido" de una obra literaria, aunque con ello no pretenda 
preterirse del todo cualesquiera otros "soportes" del hecho literario y su inserción en la circunstancia social en que él se produce.

Puede decirse también que el estilo descriptivo tiene su origen en la vocación pedagógica de José Alcántara Almánzar. Para el ámbito en el cual se mueve su crítica, este estilo es completamente imprescindible, aunque la descripción pueda parecer superabundante a quien conozca la obra comentada.

Por otra parte, toda explicación de un texto literario ha de ser siempre una interpretación, algunas veces entre nuchas posibles. Como tal, estará siempre sujeta al careo con otras interpretaciones. Lo que causa gran satisfacción en los análisis de José Alcántara es que se nota que nunca falsifica una obra en su explicación. Con mucha frecuencia, algunas interpretaciones de algunos críticos y comentaristas sufren de ser falsas ellas mismas, al mismo tiempo que falsifican la obra comentada. Y si no falsas, por lo menos gratuitas, muchas de ellas.

Una explicación tiene que ser verosímil, comprobable por la obra misma, lo cual siempre se cumple en los análisis de José Alcántara, tanto en los que incluye en este libro, como en los que están contenidos en sus obras anteriores (por ejemplo, en Estudios de Poesía Dominicana).

Una gran porción del libro que ahora ponemos en circulación está destinada a examinar la cultura que condiciona al hombre dominicano $y$, especialmente, al escritor. El lector ha de encontrar material de estudio suficiente en trabajos tales como "La Cultura Dominicana": ¿identidad o diversidad?, en el cual, con base en un trabajo de pisos de la cultura puertorriqueña, ensayo del escritor José Luis González, José Alcántara estudia los pisos imbricados de la cultura dominicana, desde el asiento indígena, del cual quedó muy poco en el criollo de las antillas mayores y menores, hasta el bombardeo actual a que el hombre está siendo sometido, magnificado, por ejemplo, por los famosos video-clips de música y su consustancial televisión por cable. Hay que leer con detenimiento este estudio de José para lograr intuir los rumbos por donde está dando tumbos el hombre dominicano de hoy, rumbos que condicionan a sus escritores y, en general, a todos nuestros artistas.

Este análisis cultural de los pisos imbricados no estaría completo si no estuviera seguido de un estudio de las coordenadas más importantes que han condicionado al hombre dominicano y de las cuales depende el escritor actual. Por ejemplo, el tema los escritores durante la dictadura 
de Trujillo es analizado por José en el libro, cubriendo desde el increíble folleto "la más bella revolución de América", título con el cual uno de nuestros buenos, y, en aquella época ingenuo, poetas saludó el movimiento con el cual Trujillo liquidó, en febrero de 1930, a la ingenua democracia dominicana de entonces, hasta la capacidad de "soñar y fabular" de escritores tales como los del grupo de la Poesía Sorprendida, movimiento éste de columpios oníricos y simbólicos y por cuya actividad todavía yo apuesto a que el escritor, y el artista en general, si escapa a la realidad que le ha tocado vivir es porque rechaza esta realidad.

Para entender al escritor de hoy, estos dos trabajos de José probarán ser completamente imprescindibles con el paso del tiempo, tal y como creo que son imprescindibles para entendernos' nosotros a nosotros mismos hoy. Es posible que algunos de los conceptos que él emite den lugar a discusiones que anticipo más o menos bizantinas, ampulosas, porque, lo que no se puede negar, es que el efecto de los pisos que José trata en el libro y las condiciones de gobernantes tales como Lilís y Trujillo han tenido demasiado peso específico en la cultura del hombre nuestro de hoy.

Ya a punto de terminar este trabajo (para tranquilidad de todos los presentes) voy a permitirme insistir otra vez: la crítica de José Alcántara Almánzar no tiene nada que ver con los problemas lingüísticos de una obra literaria; o con descubrir si algún verso está bien o mal medido; o si la espinela rima como debe de rimar; o si la estructura de un poema responde a las demandas estructurales de los estructuralistas; o a aquéllas o a éstas significaciones semióticas. No. La intención de José va dirigida a entender al hombre a través de sus escritos y de su actitud frente a la vida, no a reconocer y examinar la camisa con que este hombre se viste. Tal la razón por la cual, en vez de preocuparse por las nimiedades del estilo, o por las "fofadas" de la perfección gramatical (después de todo, es el pueblo y sus escritores quienes crean la gramática) José se ocupa de la significación misma de la obra literaria, en su decir.

Por ejemplo, el libro que hoy comentamos dedica algunas de sus páginas al examen de la obra de Manuel Rueda. No hay duda de que Manuel es uno de los poetas fundamentales nuestros, quien, en mi opinión, no ha recibido toda la atención a que es acreedor de parte de supuestos críticos y supuestos estudiosos de la literatura nacional. En el análisis de algunos de los libros de este poeta tan importante, José 
examina los conceptos fundamentales que animan a su obra: la significación de las máscaras, pongamos por caso (la concreción del enigma, como dice el propio Rueda de las máscaras, donde está el hombre y está el mundo) cuyas profundas reflexiones no han sido estudiadas en lo pasado con la seriedad requerida, no para perjuicio del poeta Rueda, sino para perjuicio de nosotros mismos que somos quienes nos perdemos las significaciones. Un crítico como José Alcántara Almánzar tiene que sentirse molesto cuando comprueba que obras tan significativas no son atendidas como se debe.

Por supuesto, el ambiente literario nuestro es uno sumamente enrarecido, lo cual ha asegurado siempre que unos a otros nos ignoremos con la más olímpica y fatal frecuencia. Algo estúpido. Algo que esperamos que a partir de la crítica de lectores agudos como José (y de literatos de las nuevas generaciones) desaparezca y que su desaparición aclare más el panorama de la literatura nacional.

Lo mismo puede decirse de la obra de Freddy Gatón Arce, a quien José también dedica páginas del libro. ¿Cómo es posible que una obra tan importante con la que está haciendo, hic et nunc, este poeta de excepción no sea comentada con más frecuencia? ¿En dónde están y qué están haciendo críticos literarios y profesores universitarios de arte y literatura?

José, como gran Quijote, quiere deshacer entuertos tales y esa es la razón, creo yo, por la cual se dedica a estudiar con pasión a estos dos poetas tan fundamentales en nuestra lengua.

Pero, ipor el amor de Dios! A mi, que cuando iba a un cine me molestaba tanto que el de al lado se dedicara a "contar" la película, cuchicheando, no en voz baja (pero valga el impropio uso del vocablo) sino en voz casi alta, con la compañera del asiento próximo, ahora me ocurre que si continúo por la pendiente por donde me estoy deslizando, voy a terminar narrándoles a ustedes el contenido del libro que hoy nos complacemos en apadrinar.

¡No! Una presentación no puede ser jamás la narración de un libro. Por tanto, yo ya he terminado. Ahora les toca a ustedes. ¿Cómo les toca?

Bien, ileed el libro!, digo yo. Y si es el caso que no vais a leerlo -cosa que irá en perjuicio de vosotros mismos porque os privará de gustar de una de las joyas críticas de nuestros tiempos- por lo menos, entonces, icompradlo!, que buena falta le hace al editor para recuperar sus costos.

iMuchas gracias! 